\title{
Special issue on pull strategies in manufacturing systems and supply chains: recent advances
}

\author{
Jose M. Framinan · Henri Pierreval
}

Received: 21 September 2011 / Accepted: 22 September 2011 / Published online: 11 October 2011

(C) Springer Science+Business Media, LLC 2011

Since the Just In Time (JIT) philosophy was born, and thanks to the success of the Toyota production system, pull control strategies have been adopted by numerous companies all over the world, both in the manufacturing and service areas. JIT paradigms and tools are also commonly taught in the engineering, business and management sections of many schools and universities. Meanwhile, if the contributions of these approaches are now well recognized, it is also commonly known that their practical benefits can be achieved only when they are applied for certain particular types of production environments. As a matter of fact, several key assumptions have to be met to ensure efficiency, such as the stability of production demand, reliable production resources, etc. Consequently, numerous production managers would be interested in exploiting the potential benefits of JIT in other types of production environments. This objective implies to be able to design new JIT methodologies and tools (or to adapt existing ones), which could cope with different types of systems or would be more robust to the violation of the classical assumptions. Thus, new pull approaches are needed, as well as modeling and optimization techniques, which would allow them to be evaluated, compared and configured. The integration of pull control in lean context or modern information systems also represents an important issue.

\section{J. M. Framinan}

Industrial Management School of Engineering,

University of Seville, Seville, Spain

H. Pierreval $(\bowtie)$

Clermont University, IFMA, LIMOS, UMR CNRS 6158, Campus des Cezeaux, BP 265, 63175 Aubière Cedex, France

e-mail: henri.pierreval@ifma.fr
Today, the markets are such that reactivity and durability are major concerns for industrial and service companies, so that numerous researchers have felt concerned with these challenges. They have continued to work intensively on defining, evaluating, integrating and optimizing pull systems. In this respect, it has appeared interesting to us to examine the current research directions and the recent advances in this area. This is the aim of this special issue, which gathers 11 papers addressing these topics.

Since Kanban was proposed, many other pull systems have been published and implemented in various companies. On the basis of an extensive literature analysis, the first article by Pedro González Rodríguez, José M Framiñán, and Henri Pierreval presents an introductory overview of pull control systems. They analyze and discuss the key principles of the existing strategies and suggest a classification of existing pull mechanisms. From this analysis, the authors draw possible important research directions in this area.

Evaluating pull strategies is important in order to be able to compare and optimize them. However their efficiency depend on the particular production system in which they are to be implemented. In their article, Arianna Alfieri and Andrea Matta propose a mathematical programming representation of the main pull control policies applied to single-product serial manufacturing systems. One of the major interests of their approach is that it can bring an interesting alternative to discrete event simulation, while providing similar types of benefits, when optimization or comparison problems have to be addressed.

How to control and synchronize the flow of materials in Kanban controlled serial production line has been addressed in several research works. In their article: "Dynamic Programming Model for Multi-stage Single-product KanbanControlled Serial Production Line" Mohammad Al-Tahat, Doraid Dalalah and Mahmoud Barghash suggest an approach 
based on dynamic programming. The production line is described as queuing network, and a dynamic programming algorithm is used to exploit the network by decomposing it into several numbers of single-stage sub-production lines. Comparisons with simulation studies are performed and several experiments are made to show the potential of their approach.

The release of orders through Kanban represents one particular aspect of the Toyota Production System. It interacts with other control mechanisms, such as Heijunka, which is also a key-element that has an impact on the performance since it levels the release of production kanbans. In this respect, in their article: "Buffer Sizing of A Heijunka Kanban System”, Judith Matzka, Maria Di Mascolo and Kai Furmans propose an approach based on a queuing network with synchronization stations to study the release of production kanbans, so as to determine their optimal number and the buffer size that guarantees a given service level.

The comparison of pull mechanisms is known to be an important issue to determine which system to use in practice. In the article: "Developing a framework for performance analysis of a production process controlled by Kanban and CONWIP", Yaghoub Khojasteh-Ghamari focuses on two strategies widely used in practice. The suggested framework is based on activity interaction diagrams (AID) and the identification of critical circuits. Initial inventories as well as card distribution are important parameters to determine the critical circuit, and hence influence the system performance. Thanks to this framework, the author provides some results comparing Kanban and CONWIP in tree-shaped production processes and serial production lines.

When a just in time orientation is adopted by a company, the workforce needed often plays an important role: how to organize employees to produce the quantity of products to meet the demand? Yufei Huang, Feng Chu, Chengbin Chu and YingluoWang address this issue in their article: "Determining the number of new employees with learning, forgetting and variable wage with a Newsvendor model in pull systems". They focus on a style-good producing factory, considering learning forgetting phenomenon and variable wages to maximize total profit. They suggest an approach for a single product and their experiments point out the consequences of the learning effect.

Uncertainty is known as a major obstacle to the implementation of JIT strategies. Such an issue is discussed in the article: "A supply chain performance analysis of a pull inspired supply strategy faced to demand uncertainties", by Guillaume Marquès, Jacques Lamothe, Carolyne Thierry and Didier Gourc. They focus on Vendor Managed Inventory (VMI), which is currently seen as a short-term replenishment pull system, and analyze its link with pull control. Uncertainty is considered in terms of trend and variability. They introduce a dedicated simulation tool for the evaluation of risks of supply chain collaboration policies, which aims at addressing such types of problems. A case study shows that in given particular contexts, VMI or Kanban can remain suited, despite the demand variability.

Pull strategies are often used in a lean manufacturing context. Brandon Stump, Fazleena Badurdeen and Fazleena Badurdeen put emphasis on the mass customization context in their article: "Integrating Lean and other Strategies for Mass Customization Manufacturing: A Case Study". They critically review the use of lean manufacturing in the context of its application to mass customization manufacturing and suggest a framework to show how other strategies such as Quick Response manufacturing/POLCA, Theory of Constraints, Flexible/Reconfigurable Manufacturing Systems, etc. can be integrated with lean to combine push and pull approaches. They present a case study of boat mass customizer that shows how the system operations are transformed by for more efficiency.

Thanks to the potential offered by information technologies in lean manufacturing contexts, certain types of pull control strategies may require a communication between manufacturing and business systems, in order to manage in time customer orders. Ahlem ZAYATI, Frédérique Biennier, Mohamed Moalla, Youakim Badr, Ahlem Zayati propose in their article "Towards Lean Service Bus Architecture for Industrial Integration Infrastructure and Pull Manufacturing Strategies" an Industrial System Integration Infrastructure, called the Lean ESB. This architecture aims at enhancing the interoperability between the production system and the global enterprise information system in terms of business and manufacturing requirements, and establishes semantic interoperability to achieve an industrial semantic.

A pull strategy can be used as a particular mechanism in a global decentralized manufacturing control context. For example, this can be the case if managers are interested in applying JIT concepts in a Job Shop whose production is organized in small series. In their article: "Pull control for Job Shop: Holonic Manufacturing System approach using multicriteria decision making", Fouzia Ounnar and Patrick Pujo suggest an approach that aims at organizing the control function. It relies on the holonic paradigm, and on an isoarchic architecture. Decision-making capacities, which use a multicriteria analysis, are integrated. Their approach is illustrated thanks to a simulation prototype, for a particular case.

Each of these articles went into a referee process and passed several rounds of referees. The guest editors would like to express their warmest acknowledgement to all the international experts that have accepted to act as reviewers and to all the authors that have submitted their work to this special issue. We are also grateful to the Editor in Chief of 
the journal for providing us the opportunity to publish this special issue.

These articles present new results that should be useful for both researchers and production managers. We hope that they will bring a contribution to the current industrial practices and will stimulate new ideas. 